\title{
Major Threats Facing Terrestrial Mammals in Canada
}

\author{
ISTVÁN IMRE ${ }^{1,3}$ and DARREN DERBOWKA ${ }^{2}$
}

${ }^{1}$ Department of Biology, Algoma University, 1520 Queen Street East, Sault Ste. Marie, Ontario P6A 2G4 Canada

${ }^{2}$ Ontario Forest Research Institute, Ontario Ministry of Natural Resources, 1235 Queen Street East, Sault Ste. Marie, Ontario P6A 2E5 Canada

${ }^{3}$ Corresponding author: (tel.: 705-949-2301 ext. 4341; fax: 705-949-6583; email: istvan.imre@algomau.ca)

Imre, István and Darren Derbowka. 2011. Major threats facing terrestrial mammals in Canada. Canadian Field-Naturalist 125(3): 213-219.

Largely due to influences related to dramatic human population growth, threats to many species are on the rise globally. An examination of mammals assessed by the Committee on the Status of Endangered Wildlife in Canada (COSEWIC) determined the major threats facing terrestrial mammal populations in Canada. Significant threats were associated with habitat loss and overall mortality caused directly by humans. Carnivores and rodents differed substantially in mortality caused directly by humans and loss of food resources. Large mammals were more affected by climate change than small mammals.

Key Words: terrestrial mammals, threats, Committee on the Status of Endangered Wildlife in Canada, COSEWIC, Species at Risk Act, species at risk, habitat loss, habitat fragmentation, loss of food, Canada.

Mammals are among the best known and recognizable groups of animals on the planet, and they are more readily studied than other organisms. People's attitudes toward other mammals have changed significantly since historical times. Local people predominantly used mammals for food or various artifacts (e.g., Robinson and Redford 1991), and mammals often formed an important component of culture or religion (Cuarón 2008).

Increasing global human populations have been associated with extensive habitat disturbance related to changes in land cover, agriculture, rampant resource extraction, and extensive fragmentation of the remaining forests. Habitat loss and modification are considered among the leading threats to all species globally, including mammals (Primack 2006). Mammalian species diversity, abundance, and total and mean biomass tend to decrease with increasing human disturbance of the landscape (Chiarello 2008; Laurance et al. 2008; Lopes and Ferrari 2008). In addition to the indirect negative effect of human activities through habitat disturbance, humans in many poor areas of the world rely to an ever increasing extent on hunting and poaching of mammals for food or trade. For example, the multibillion-dollar trade in bushmeat, i.e., the meat of terrestrial wild animals (including primates), hunted and killed for subsistence (food) or for commercial purposes, is an important contribution to the economy of the developing world, and hunting for bushmeat is considered one of the most important threats to the survival of tropical vertebrates, including mammals (Brashares et al. 2004). Similarly, poaching has been shown to reduce substantially the abundance of mammal populations in high demand (Wright et al. 2001).

There are now more than 45000 animal species of concern listed on the Red List of the International
Union for Conservation of Nature (International Union for Conservation of Nature 2011). Largely due to influences related to dramatic growth in the human population, threats to many species are on the rise globally. Currently, it is estimated that $1.6 \%$ of the world's mammal species have become extinct since the year 1600 (Primack 2006), a period associated with the advent of the industrial revolution and marked increases in global human populations. The analysis of 114 countries done by McKee et al. (2003) revealed that the number of species classified by the IUCN as threatened (i.e., critically endangered, endangered, or vulnerable) in the average nation would rise roughly $14 \%$ by the year 2050 as a direct result of human population growth alone, further indicating the trend in species extinctions is expected to continue into the future.

While the IUCN is the watchdog of the status of wildlife populations worldwide, the Committee on the Status of Endangered Wildlife in Canada (COSEWIC) is responsible for monitoring species at risk of extinction in Canada. In 2003, the Canadian government passed the Species at Risk Act (SARA), which provides the legal means through which species assessed by COSEWIC are afforded protection and targeted for recovery. By examining the species in the COSEWIC database and the information on the Species at Risk Public Registry, we investigated the types of threats facing terrestrial mammal populations in Canada and determined which categories of threat were posing the most substantial risk to these animals. Further, to determine whether types of threats facing different groups of animals differ, we compared carnivores and rodents and large-bodied mammals with small-bodied mammals. Finally, we evaluated the conservation measures implemented under the Species at Risk Act in Canada to see whether they are likely to address the negative trends noted in Canadian mammals at risk. 


\section{Materials and Methods}

To determine the types of threats facing terrestrial mammals in Canada, we retrieved data from the COSEWIC database (http://www.cosewic.gc.ca/eng/ sct5/index_e.cfm). Using the search engine provided, we obtained a list of species assessments that included extirpated, endangered, threatened, and special concern. All status categories were defined by COSEWIC. The extirpated designation is given to a species that no longer exists in the wild in Canada but that occurs elsewhere. Endangered species face the immediate threat of extirpation or extinction within Canada. Threatened species include those organisms that can be expected to become endangered if limiting factors are not mitigated. Lastly, species of special concern include species that may become threatened or endangered because of a combination of biological characteristics and identified threats. Mammals that are extinct or extirpated were not included in this study, as current threats to extant mammals were desired rather than historical factors.

After the list had been compiled, we obtained specific threat data for each species from the Species at Risk Public Registry (http://www.sararegistry.gc.ca/ default_e.cfm), which describes the threats currently affecting each species. Broad categories of threat were designated, as identified in each of the website's threat descriptions. A frequency distribution table of species by threat category was generated using a designation of 1 to indicate impact by a particular threat category or left blank to indicate no impact. A species could be affected by a particular threat category only once, even if multiple threats described were identified within the same category.

We used the designatable units (sensu Green 2005) as specified on the Species at Risk Public Registry. It is important to note that these units can be certain populations of a species or a subspecies, but will be referred to as "species" in this study. For example, four different populations of the Woodland Caribou (Rangifer tarandus caribou) are listed as designatable units, with different levels of endangerment: the Northern Mountain population is of special concern, the Boreal and Southern Mountain populations are threatened, and the Atlantic-Gaspésie population is endangered.

Threat data were collected from species assessment reports prepared by COSEWIC as well as the shorter species accounts provided on the Species at Risk Public Registry. The data collection and analyses were limited to actual and imminent threats. For example, the Plains Bison is not currently affected by disease, but the likelihood of Plains Bison contracting tuberculosis, brucellosis, or anthrax from nearby domestic cattle herds is very high; therefore, disease was included as an imminent threat for this species. Species with no current threats or imminent threats were not included in the analysis. For example, the Spotted Bat (Euderma maculatum) was removed from our list because there is no strong evidence supporting the threats in its species account.

A total of 11 categories of threat were identified as affecting mammals at risk assessed by COSEWIC in Canada: 1) habitat alteration or loss, 2) direct humancaused mortality, 3) habitat fragmentation, 4) predation, 5) loss of food resources, 6) climate change, 7) small population size, 8) invasive species, 9) disease, 10) hybridization, and 11) northern extent of range. Included under Habitat alteration or loss were such threats as urban development, agriculture, deforestation, and human population growth that have reduced the overall land base available for habitat and/or have altered the system in such a manner that it is no longer suitable for species habitation. Direct human-caused mortality involved threats such as hunting, trapping, motor vehicle collisions, and targeted exterminations. Habitat fragmentation was included as its own threat category because of its frequent appearance in species accounts. Habitat fragmentation represents a very specific circumstance of habitat alteration where habitat has been increasingly divided into smaller and smaller units. The Predation category of threat included pressures from naturally established predator-prey relationships that may have been exacerbated by other human-induced impacts. Threats under Loss of food resources are the result of the loss of prey organisms and plants. This threat affects both carnivores/omnivores and herbivores, and these losses may be a direct result of impacts caused by humans. Threats from Climate change were broadly inclusive and not well defined in species accounts, but generally were expected to contribute to habitat alteration. Threats under Small population size stemmed from loss of genetic variability, demographic variation, and magnitude of natural catastrophes. Invasive species threatened mammals by directly competing for resources or by preying directly upon them. Disease was reported as a native threat that could exacerbate species decline. Hybridization included interbreeding with related species, resulting in reduced vigour and introgression. Lastly, Northern extent of range was reported as a threat to those species with populations struggling at their northernmost tolerance limits.

The taxonomic order was also identified for each species, along with the average adult body mass. Body mass data were collected from the COSEWIC assessment reports or the species accounts on the Species at Risk Public Registry or from Banfield (1977). Where differences in average body mass were reported by sex, mass was determined by averaging the mass of adult males and females.

Collected frequency data were summarized to show the overall proportion of impacts that each threat category posed for mammal species at risk in Canada. Total frequency data were also summarized to show the percentage of all species that was reported as being affected by each threat category. Frequency data were likewise summarized for large mammals $(>10.0 \mathrm{~kg})$ 
and small mammals $(<10.0 \mathrm{~kg})$ and for mammals in the orders Carnivora and Rodentia. Body size threshold was selected based on clustering of the data.

We compared the proportion of affected carnivores and rodents and large and small mammals, respectively, for any given threat category using $2 \times 2$ contingency tables. On several occasions, more than $20 \%$ of the categories contained frequencies less than about five; therefore, in addition to the $\chi^{2}$ analyses, we also computed Yate's correction for continuity as well as Fisher's exact test (Quinn and Keough 2002). The latter two tests supported the findings of the regular $\chi^{2}$ test in all instances; hence we reported only the results of the $\chi^{2}$ tests. The value of $\alpha$ was set at 0.05 .

\section{Results}

In Canada, there are 32 terrestrial mammal species and subspecies at risk (including the Spotted Bat) assessed by COSEWIC. Excluding the Spotted Bat, there were 10 endangered, 9 threatened, and 12 species of special concern (Table 1). The order Carnivora had the most species in this study, with 11. Artiodactyla was second with 8 species, followed by Rodentia with 7, Soricomorpha with 3, and Chiroptera and Lagomorpha with 1 each (Table 1). A total of 13 largebodied mammal species $(>10 \mathrm{~kg})$ and 18 small bodied animals $(<10 \mathrm{~kg})$ were examined in this study, with average body weights (SD) of $231.8 \mathrm{~kg}$ (SD 239.9) and $1.44 \mathrm{~kg}$ (SD 2.09), respectively (Table 1).

On average, 2.7 categories of threat (SD 1.1) affected each of the identified terrestrial mammal species at risk. Threats in the Habitat loss category affected $84 \%$ of species (Figure 1). Direct human-caused mortality ranked second, with $58 \%$ of species experiencing this threat type (Figure 1).

Several differences in the frequency of reported threats to species in Carnivora and Rodentia appeared to be substantial upon visual inspection (Figure 2). Direct human-caused mortality affected a significantly higher proportion $\left(\chi^{2}=10.57, \mathrm{df}=1, P=0.001\right)$ of carnivores $(91 \%)$ than rodents (14\%) in Canada. Furthermore, a large proportion of carnivores $(55 \%)$ were threatened by Loss of food resources but no rodents were reported as being affected by this threat type $\left(\chi^{2}\right.$ $=5.73, \mathrm{df}=1, P=0.017)$. Differences in the other threat categories were not significant (data not shown).

Some differences in reported threat frequencies also appeared in the comparison of large-bodied and smallbodied mammals (Figure 3 ). Climate change affected a significantly larger proportion $\left(\chi^{2}=6.36, \mathrm{df}=1, P\right.$ $=0.012)$ of large-bodied mammals $(31 \%)$ than smallbodied mammals $(0 \%)$. Differences in the other threat categories were not significant (data not shown).

\section{Discussion}

Data from the International Union for Conservation of Nature, which examines 245 countries for the number of critically endangered, endangered, or vulnerable species, showed that Canada had more mam- mal species in these categories than $69 \%$ of examined nations worldwide (table 5, International Union for Conservation of Nature 2011). Interestingly, this placed Canada at par with several third world nations, such as Guinea Bissau, Mali, Mozambique, Namibia and Niger. However, it is likely that different levels and quality of documentation in different countries may influence these data. In comparison with large developed countries with conservation data of similar quality to those from Canada, like Australia (55 mammals) and the United States (37 mammals), Canada had a markedly lower number of critically endangered, endangered, or vulnerable mammals (12) (table 5, International Union for Conservation of Nature 2011). In addition, it is important to note that there are substantial differences among these countries in population density and overall area.

McKinney (2002) observed that human population size increases with land area and is strongly correlated with the proportion of species classified by the IUCN as threatened (i.e., critically endangered, endangered, or vulnerable) among nations. It is reasonable to expect that both habitat loss and direct human-caused mortality would also rise with increasing population density, both of which represented the most significant reported threats to mammals at risk in this paper. In another study examining 114 continental nations, approximately $88 \%$ of the variation in the number of mammal and bird species at risk was explained by human population density and species richness variables (McKee et al. 2003). Population extinctions have been linked to population density and the associated impacts of agriculture, hunting, and grazing, particularly in Southeast Asia, where more than half of its examined land base had lost $75 \%$ to $100 \%$ of its mammal species (Ceballos and Ehrlich 2002). Habitat loss and fragmentation are also significant threats to mammals in Brazil, which boasts the world's largest diversity of known mammals, with 530 described species (Costa et al. 2005).

Canada is one of the last places on Earth with large wilderness areas and a small average human population density, yet the number of species classified by the IUCN as threatened (i.e., critically endangered, endangered, or vulnerable) continues to rise. Kerr and Deguise (2004) measured habitat loss within the ranges of 243 terrestrial species (including mammals) assessed by COSEWIC as endangered, threatened, or special concern across Canada and found that less than $50 \%$ of the species' ranges was still natural habitat; no detectable natural habitat remained for 16 of the 243 species. In addition, the authors found that habitat loss explained most of the variation in the number of endangered species per ecozone in Canada and concluded that habitat loss within a species' range is likely to be the most important factor that prevents its recovery (Kerr and Deguise 2004). 


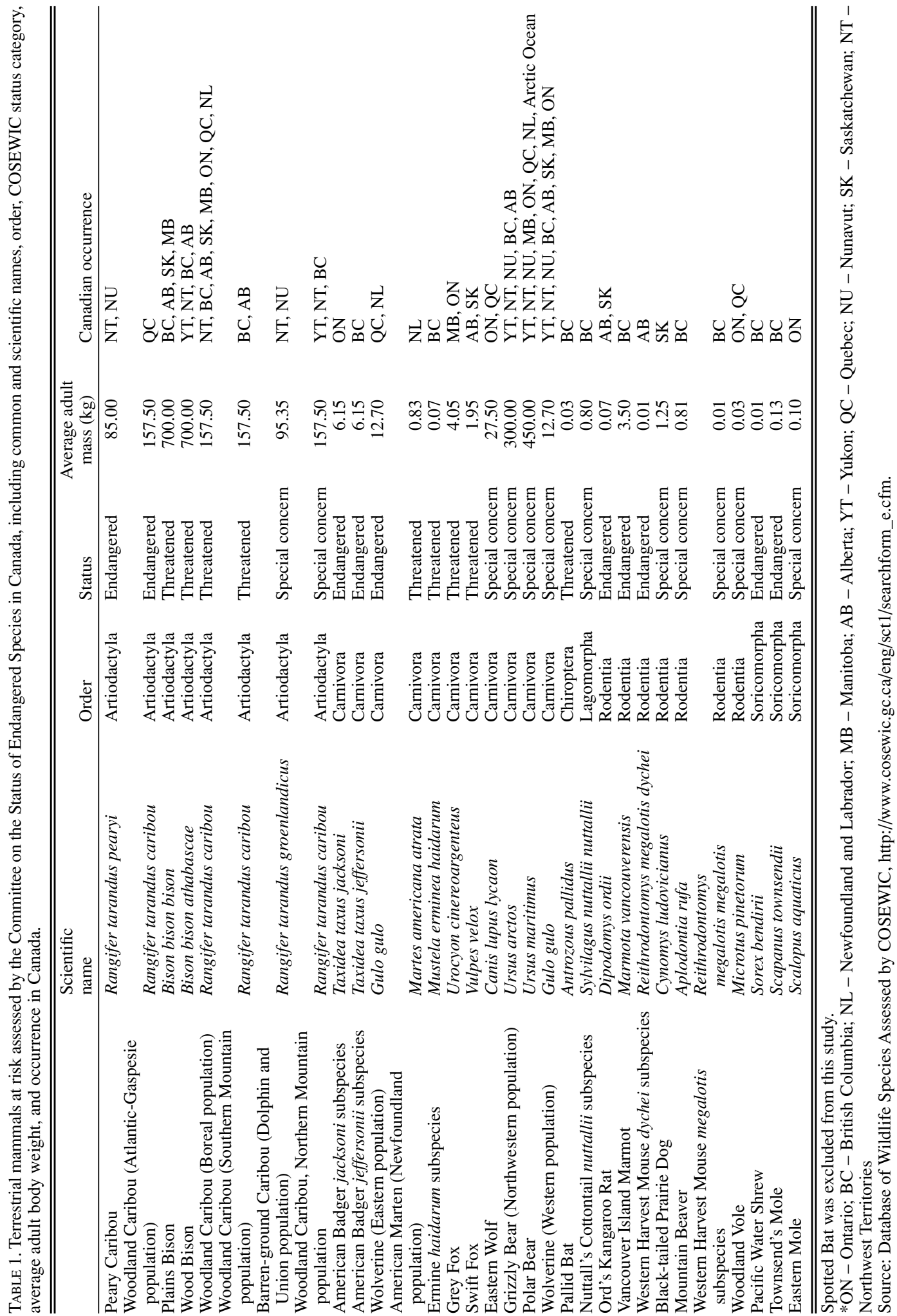




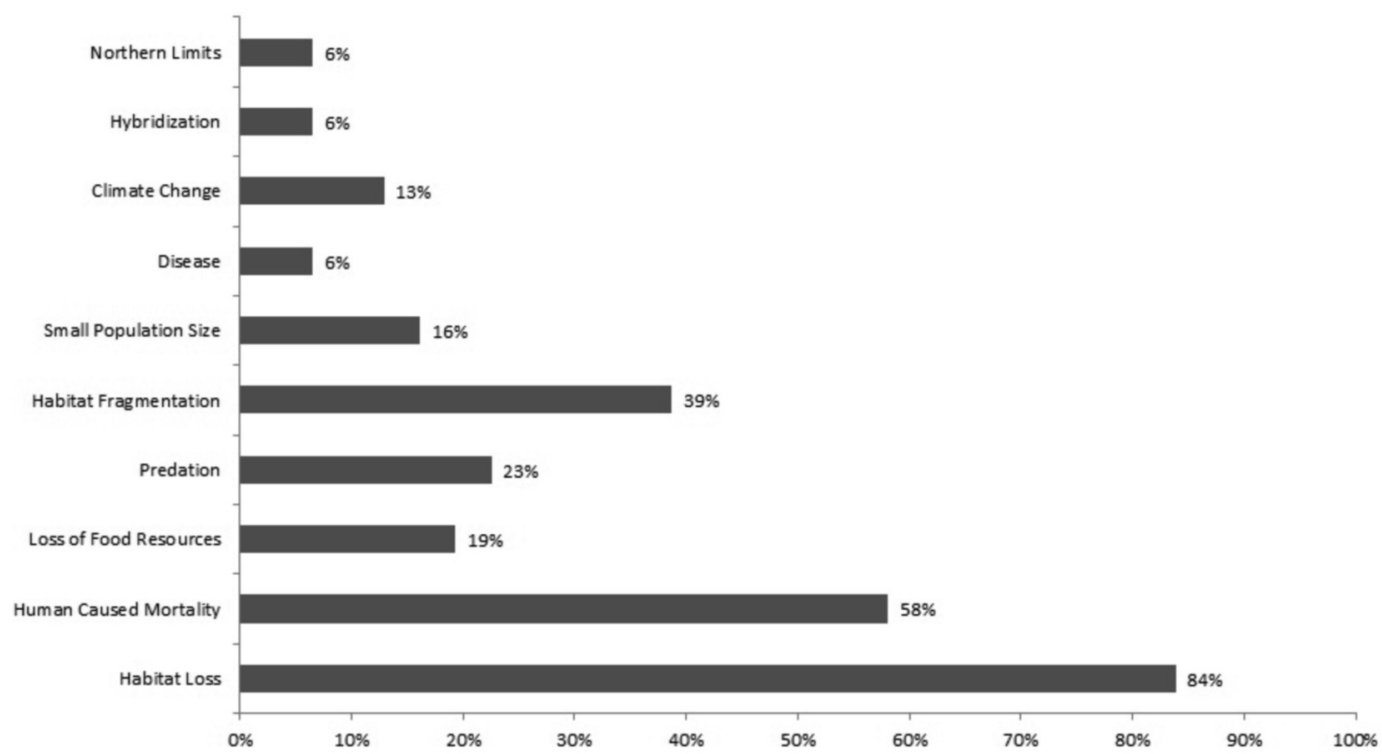

FIGURE 1. Percentage of terrestrial mammal species at risk (assessed by the Committee on the Status of Endangered Wildlife in Canada) impacted by different threat types.

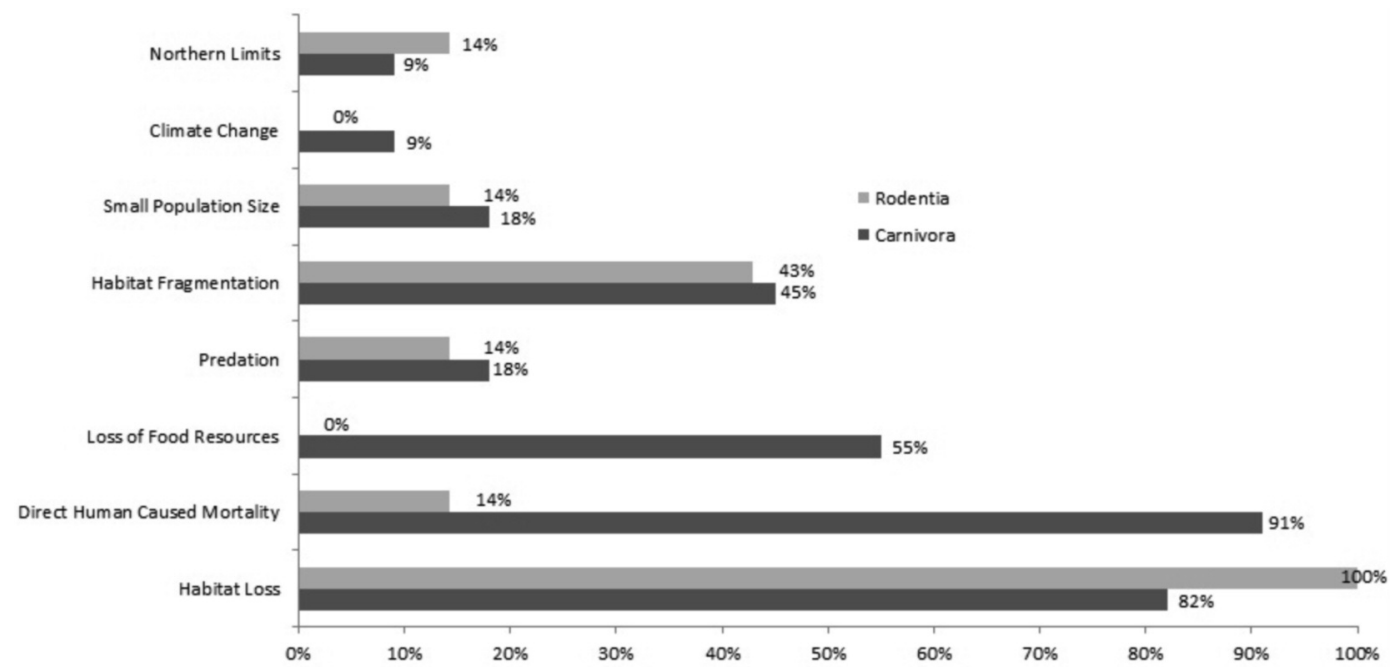

FIGURE 2. Percentage of terrestrial carnivore and rodent species at risk (assessed by the Committee on the Status of Endangered Wildlife in Canada) impacted by different threat types.

Another recent study used remote sensing and species distribution datasets to examine the influence of natural and anthropogenic factors on the density of species assessed by COSEWIC as endangered (including terrestrial mammals) in Canada (Kerr and Cihlar 2004). In addition, Kerr and Cihlar (2004) examined the capacity of protected areas to shelter endangered species. The authors found a strong positive relation- ship between the density of terrestrial endangered species and agricultural land use, with the latter relating strongly to habitat loss as well as land use intensity. There was no relationship between densities of endangered species and the extent of protected area in watersheds. However, there are virtually no protected areas in the watersheds with the highest concentration of endangered species (Kerr and Cihlar 2004). The latter 


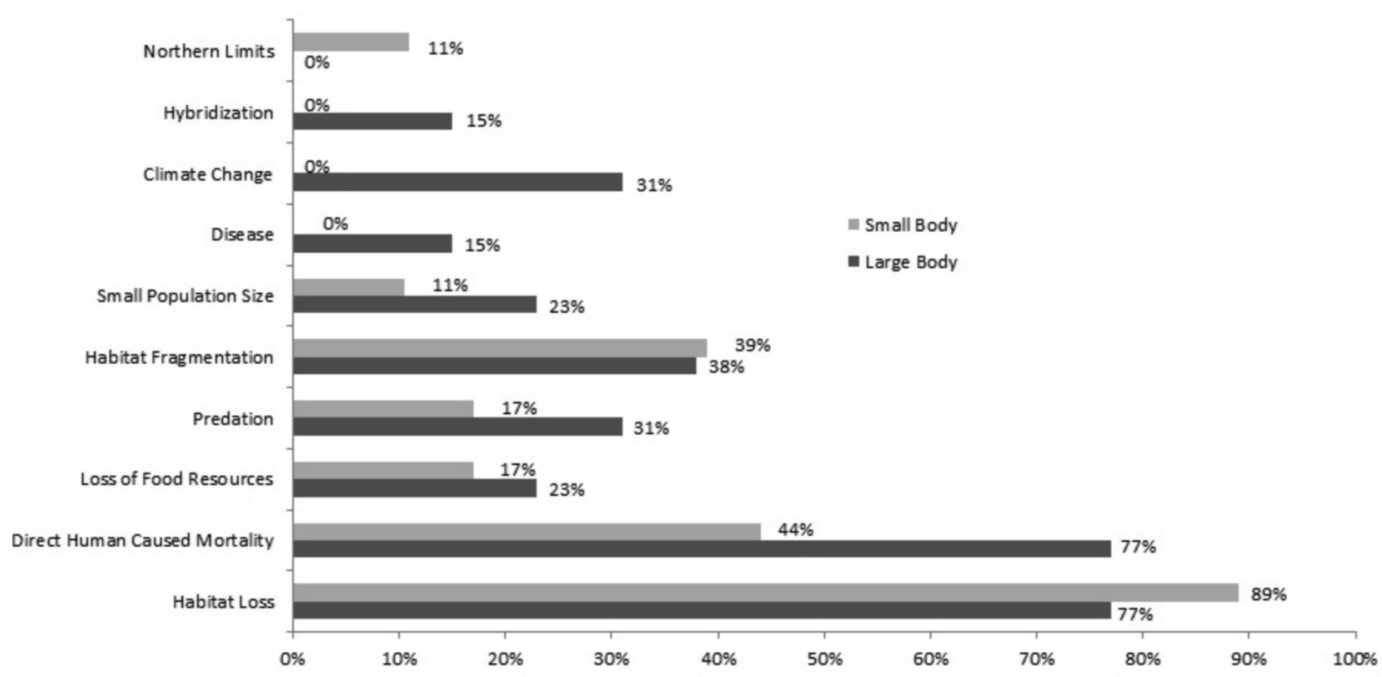

FIGURE 3. Percentage of terrestrial large and small mammals at risk (assessed by the Committee on the Status of Endangered Wildlife in Canada) impacted by different threat types.

findings suggest that existing protected areas have little, if any, potential to reduce extinction rates in Canada (Kerr and Cihlar 2004). The authors concluded that the Species at Risk Act appears to provide habitat protection in an inverse proportion to the needs of endangered species in Canada, with federal lands (which are most readily protected under the Act) being extensive in areas with few endangered species and being very rare in areas with a high number of endangered species.

Can the Species at Risk Act address the leading threats identified in this study? The Act has a limited ability to provide for habitat protection in areas that have already undergone extensive habitat changes due to urbanization and agriculture. Improvement to reserve networks as well as cooperative conservation activities with private landowners are possible avenues for avoiding the rapid extinction of endangered species in Canada (Kerr and Deguise 2004). In terms of mortality caused by humans, the Act is sufficient to stop overexploitation or targeted extermination of a species because it prohibits the killing, harming, or capturing of species declared to be threatened, endangered, or extirpated; however, it cannot prevent indirect sources of human-caused mortality, such as trapping by-catch or collisions with automobiles.

\section{Carnivores and rodents}

Resiliency to interaction with human populations will be an increasingly important trait in determining survival of species into the future. Cardillo et al. (2004) pointed out the importance of biology in the persistence of species faced with increasing human population densities and cited carnivores as being particularly at risk for future extinctions. Biological traits, including small geographic range size, low species popula- tion density, and high trophic level, explained approximately $45 \%$ of the variation in extinction risk in carnivores. For carnivore species with high exposure to human populations, however, the addition of gestation length as a factor increased the explanatory power of the model to $80 \%$ (Cardillo et al. 2004). Although Cardillo et al. (2004) studied species of carnivores in Africa, their findings are relevant to Canada: carnivores had the most species in the current study. Further, for $91 \%$ of the carnivores at risk assessed by COSEWIC, threats related to direct mortality caused by humans were cited as a reason for reduced abundance. Habitat loss was also a factor in $82 \%$ of carnivores at risk assessed by COSEWIC.

Some interesting differences in threat categories were observed between carnivores and rodents in this study. While direct human-caused mortality was reported in almost every instance for carnivores, there were far fewer rodents that were affected by threats in this category. This observation is not surprising, as many large carnivorous mammals are hunted for trophy sport or eradicated due to livestock predation, as is the case for Jaguars (Panthera onca) in Brazil (Costa et al. 2005). Certainly, this has been the case for Grizzly Bears (Ursus arctos) and Eastern Wolves (Canis lupus lycaon) in Canada (Species at Risk Public Registry 2011). Even subsistence hunting has been shown to have a negative impact on mid-sized and large vertebrates, particularly when habitats become fragmented by human activity (Peres 2001).

Another observation of note showed loss of food resources as a threat in $55 \%$ of carnivore species, while rodents were not affected at all by this category of threat. Brashares (2003) also found mammals with 
larger home ranges were more prone to extinction. Carnivores require more extensive home ranges over which prey must persist or be accessible, and this may explain the significance of this threat to these mammals. Rodents on the other hand have smaller home ranges and generally less specific diets than carnivores.

Cardillo et al. (2005) reported that body size was another trait positively associated with high risk of extinction for mammals larger than $3 \mathrm{~kg}$. However, Brashares (2003) found no relation between body size and the persistence of species in the wild. We observed no significant difference in the two major categories of threat between large and small-bodied mammals, suggesting that smaller body size may indeed provide very little protection against major species threats.

One limitation of our data is that the sample size is quite small for broad generalizations, and caution is therefore recommended in the application of these findings. Better data on threats to species at risk would require more research on existing levels of threat. However, these data appear overall to be representative of the major threats that exist elsewhere in the world and point to the need for better understanding of these threats and how they can be mitigated within Canada and globally. A major obstacle to mitigation is that many threats to mammals are correlated with one another, and synergistic effects are highly probable in most circumstances. What cannot be denied is that the origin of these increasing impacts is growth of human populations and the resulting pressures people are placing on global resources.

In conclusion, the major threats facing species at risk in Canada are habitat loss and alteration and direct human-caused mortality. Carnivores and rodents showed substantial differences with respect to direct human-caused mortality and loss of food resources. Differences in threat based on body size did not appear significant for the two major threats identified in this study, but were more substantial for threats due to climate change.

\section{Literature Cited}

Banfield, A. W. F. 1977. The Mammals of Canada. University of Toronto Press, Toronto, Canada. 438 pages.

Brashares, J. S. 2003. Ecological, behavioural, and life-history correlates of mammal extinctions in West Africa. Conservation Biology 17(3): 733-743.

Brashares, J. S., P. Arcese, M. K. Sam, P. B. Coppolillo, A. R. E. Sinclair, and A. Balmford. 2004. Bushmeat hunting, wildlife declines, and fish supply in West Africa. Science 306: 1180-1183.

Cardillo, M., A. Purvis, W. Sechrest, J. L. Gittleman, J. Bielby, and G. M. Mace. 2004. Human population density and extinction risk in the world's carnivores. PLoS Biology 2(7): 909-914.

Cardillo, M., G. M. Mace, K. E. Jones, J. Bielby, O. R. P. Bininda-Emonds, W. Sechrest, C. D. L. Orme, and A. Purvis. 2005. Multiple causes of high extinction risk in large mammals. Science 309: 1239-1241.

Ceballos, G., and P. R. Ehrlich. 2002. Mammal population losses and the extinction crisis. Science 296: 904-906.
Chiarello, A. G. 2008. Density and population size of mammals in remnants of Brazilian Atlantic forest. Conservation Biology 14: 1649-1657.

Costa, L. P., Y. L. R. Leite, S. L. Mendes, and A. D. Ditchfield. 2005. Mammal conservation in Brazil. Conservation Biology 19(3): 672-679.

Cuarón, A. D. 2008. A global perspective on habitat disturbance and tropical rainforest mammals. Conservation Biology 14: 1574-1579.

Green, D. M. 2005. Designatable units for status assessment of endangered species. Conservation Biology 19: 18131820 .

International Union for Conservation of Nature (IUCN). 2011. Summary statistics for globally threatened species, table 5. http://www.iucnredlist.org/documents/summary statistics/2011_2_RL_Stats_Table5.pdf (accessed on 21 July 2011).

International Union for Conservation of Nature (IUCN). 2011. Table 3a. Status category summary by major taxonomic group (animals). IUCN Red List version 2011.1. http://www.iucnredlist.org/documents/summarystatistics/ 2011_1_RL_Stats_Table_3a.pdf (accessed 21 July 2011).

Kerr J. T., and J. Cihlar. 2004. Patterns and causes of species endangerment in Canada. Ecological Applications 14: 743753.

Kerr J. T., and I. Deguise. 2004. Habitat loss and limits to endangered species recovery. Ecology Letters 7: 11631169.

Laurance W. F., S. G. Laurance, and D. W. Hilbert. 2008. Long-term dynamics of a fragmented rainforest mammal assemblage. Conservation Biology 22: 1154-1164.

Lopes M. A., and S. F. Ferrari. 2008. Effects of human colonization on the abundance and diversity of mammals in eastern Brazilian Amazonia. Conservation Biology 14: 1658-1665.

McKee, J. K., P. W. Sciulli, C. D. Fooce, and T. A. Waite. 2003. Forecasting global biodiversity threats associated with human population growth. Biological Conservation 115: 161-164.

McKinney M. L. 2002. Why larger nations have disproportionate threat rates: area increases endemism and human population size. Biodiversity Conservation 11: 1317-1325.

Peres, C. A. 2001 Synergistic effects of subsistence hunting and habitat fragmentation of Amazonian forest vertebrates. Conservation Biology 15(6): 1490-1505.

Primack, R. B. 2006. Essentials of Conservation Biology. Fourth ed. Sinauer Associates, Sunderland.

Quinn, G. P., and M. J. Keough. 2002. Experimental design and data analysis for biologists. Cambridge University Press, New York.

Robinson, J. G., and K. H. Redford. 1991. Neotropical wildlife use and conservation. Chicago University Press, Chicago.

Species at Risk Public Registry. 2011. Status reports. http://www.sararegistry.gc.ca/sar/assessment/status_e.cfm (accessed on 21 July, 2011)

Wright S., H. Zeballos, I. Domínguez, M. M. Gallardo, M. C. Moreno, and R. Ibáñez. 2001. Poachers alter mammal abundance, seed dispersal, and seed predation in a neotropical forest. Conservation Biology 14: 227-239.

Received 1 January 2011

Accepted 10 April 2011 